\title{
CONSUMER DESIRE FOR LUXURY BRANDS: INDIVIDUAL LUXURY VALUE PERCEPTION AND LUXURY CONSUMPTION
}

\author{
Nadine Hennigs, Leibniz University Hannover, Germany \\ Christiane Klarmann, Leibniz University Hannover, Germany \\ Stefan Behrens, Leibniz University Hannover, Germany \\ Klaus-Peter Wiedmann, Leibniz University Hannover, Germany
}

\begin{abstract}
Along with the rising global appetite for luxury brands, luxury brand managers have to balance the tremendous demand for their goods in the global marketplace without threatening the key characteristics of exclusivity and uniqueness that are necessary preconditions of luxury. With respect to the serious challenges inherent in luxury brand management such as the risks of brand over-extensions and counterfeiting, an integrative understanding of luxury and the multifaceted desires an individual seeks through luxury consumption are key success factors in luxury brand management. Recent research gives evidence that the desire for and the consumption of luxury brands involves several dimensions of customer perceived value including financial, functional, individual, and social consumer perceptions. Nevertheless, to date, the interplay of the customer perceived value dimensions and the assessment of their effects on individual luxury value perception and related behavioral outcomes are poorly understood and widely unexplored.
\end{abstract}

Against this backdrop, incorporating relevant theoretical and empirical findings, this study focuses on the investigation of the interplay of the customer perceived value dimensions (financial, functional, and social value) and the assessment of their effects on individual luxury value perception and related behavioral outcomes (purchase intention, recommendation behavior, willingness to pay a price premium). The paper is structured as follows: first, the conceptual model and related hypotheses are presented based on existing research insights on luxury brands and customer perceived value; second, the methodology and results of our empirical study are described. Third, the analysis results are discussed with reference to managerial implications and further research steps.

To measure the antecedents and outcomes of individual luxury value perception, we used existing and tested measures. Items were rated on five-point Likert scales $(1=$ strongly agree, $5=$ strongly disagree). The first version of our questionnaire was face-validated using exploratory and expert interviews to check the length and layout of the questionnaire and the quality of the items used. To investigate the research model, an online questionnaire was conducted among consumers in Germany in July 2012. A total of 782 questionnaires were received.

In our study, SPSS 19.0 and PLS structural equation modeling (SmartPLS 2.0) were used to analyze the data. A reliable and valid measurement of the latent variables was confirmed. Referring to the antecedents of individual luxury value perception, our results verify that the perceived financial, functional and social value of luxury brands are significantly positive related to the key construct of individual luxury value perception. Morover, the individual luxury value perception has a positive impact on purchase intention, recommendation behavior, and the willingness to pay a price premium. With reference to the evaluation of the inner model, the coefficients of the determination of the endogenous latent variables (R-square) reveal satisfactory values at .637 for individual luxury value perception, .618 for purchase intention, .565 for recommendation behavior, and .526 for the willingness to pay a price premium. Moreover, Stone-Geisser's Q-square yielded a value higher than zero for the endogenous latent variables, suggesting the predictive relevance of the explanatory variables.

The results presented here have important implications for luxury brand management and future research in the domain of luxury goods. By addressing the specific value aspects that are highly relevant for consumer loyalty to the brand, a luxury company can stimulate purchase behavior with appropriate marketing campaigns that emphasize the most important value aspects. In this context, a study focusing on different luxury brands, different luxury industries or the comparison luxury vs. necessity might enhance current knowledge of consumer behavior in the luxury industry. On an international level, the specific consideration of cultural issues is required and therefore, possible cross-cultural similarities and differences have to be examined in future research to generalize the results and to sell successfully luxury goods to consumers of different nationalities. 